\title{
Using diaries in intensive care: A method for following up patients
}

Sissel Lisa Storli RN, MSc Doctoral Student/Research Fellow, Intensive Care Nurse Department of Nursing and Health Sciences N-9037 University of Tromsø, Norway Ranveig Lind RN, MSc Head Nurse, Intensive Care Unit, N-9038 University Hospital of North Norway, Tromsø, Norway Inga-Lill Viotti RN Intensive Care Nurse, Leader, Follow-Up Management Group, Intensive Care Unit, N-9038 University Hospital of North Norway, Tromsø, Norway

E-mail: sissels@fagmed.uit.no

Key words: ICU follow-up * intensive care * memory patient diary recollections of ICU

\section{SUMMARY}

* Patients' recollections of intensive care are often a confusing mixture of 'reality', past experiences and vivid dreams.

* Many intensive care patients find it difficult to make sense of their experiences.

* In our intensive care unit, for several years, we have been using patient diaries to record the patient's stay in intensive care.

* The diaries are utilised as part of a follow-up programme that helps the patient to understand, and come to terms with, their intensive care admission.

* The diaries have been positively evaluated by both patients and staff, and are a valuable tool for learning from patents' experiences.

\section{INTRODUCTION}

This paper was developed from a poster presentation given in Paris in 2002 at the 1st Conference of the European Federation of Critical Care Nursing Associations (Storli 2002).

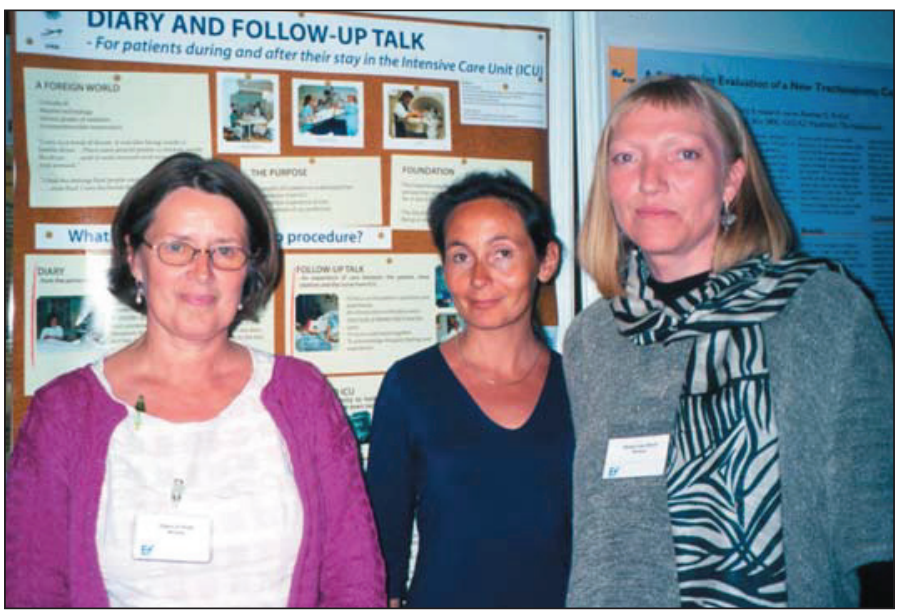

Poster presentation in Paris. From the left: Inga-Lill Viotti, Ranveig Lind and Sissel Lisa Storli.
The last ten years have seen much progress in intensive care treatment - both medical and pharmaceutical. These developments have enabled us to extend and save many lives. Nursing care is a primary and priority function within intensive care units (ICUs) and nurses are increasingly aware that there is something more that can be done to improve the outcome of patients beyond technological caring. For example, the support of relatives, caring relationships, and feelings of hope and trust are a fundamental part of human existence, and are all important determinants that affect both quality of life and patient outcomes. These are realms that challenge us in our everyday practice (Løgstrup 1956, Gjengedal 1994, Granberg et al. 1998, Granberg et al. 1999, Storli 2002).

There is a myth that patients do not remember anything from intensive care. We now know that they do remember. However, what they remember is often disjointed and seems to be more like a jigsaw puzzle than a chronological or orderly recollection of events. Memories of ICU are often a chaotic mixture of unusual sensual impressions, dreams, previous life-experiences and what we (as nurses) know to be real events (Granberg et al. 1999, Storli 2002). This mixture of experiences represents an 'astonishing journey' for many ICU patients (Storli 2002). There is often evidence of 'corporeal memory' - the body experiences more than the intellect remembers. For example, if a patient is asked if he remembers being on the ventilator, he will often have no recollection. However, by enabling him to visit the ICU, and exposing him to the sounds of the ventilator working, it can bring back his forgotten feelings of struggling for breath.

The French philosopher Merleau-Ponty (1962) stated that we are in the world bodily i.e. physically - not just as cognitive beings and that our body remembers. In this way, memory can be understood as being embodied. The human body is the medium for our temporal and spatial communication and is therefore significant in the function of memory. Memory is 'an effort to reopen time on the basis of the implications contained in the present' (Merleau-Ponty 1962 p.181). In the same way, we can understand how previous life experiences can be awakened and how they intermingle with ICU events, becoming actual and real experiences. Merleau-Ponty (1962 p.151) compares our body to a work of art, stating that our 
body 'is a focal point of living meanings'.

We also know, through our own experience of following up patients, that people often seem to struggle with their lives after intensive care. The nature and degree of their problems are variable, but the struggle to realise and understand what they have been living through is a common problem (Compton 1991, Daffurn et al. 1994, Jones et al. 1998, Jones et al. 2001).

\section{BACKGROUND}

In 1996 we undertook a clinical study that examined the use of patient diaries as a tool to help patients understand their intensive care experience (Lind \& Storli 1999). The study was evaluated very positively, and since January 2000 the use of patient diaries has been an established part of nursing in our ICU (Storli 2000).

Thirty-two patients were included in the original study that was responsible for the initiation of our diary/follow-up programme. The study was important in that it provided us with valuable information concerning the positive benefits to patients of using diaries and follow-up discussions. The study opened up patient accounts of 'madness experiences', which individual patients often thought were unique to them. Our findings were that there was a strong relationship between confusing and astonishing experiences and real events. Patients also found memory relationships between their ICU experiences and previous life-experiences.

Through engaging in the programme, patients were able to realise, to some extent, what had really happened to them. Thus some confusing and frightening experiences could be understood as normal phenomena. The follow-up programme also helped patients to gain a clearer, more realistic insight into the period of severe illness or injury, which made them better prepared for the challenging period of recovery that lay ahead. It also helped both patients and relatives to integrate the ICU period into their own life histories, making the experiences possible to understand and making them their own. Similar findings were reported in a Swedish study using diaries (Bergbom et al. 1999). Patients also highlighted that it meant so much to them that the staff took the time to do this for them. Of all patients surviving ICU, none rejected the diary.
The four-fold purpose of using patient diaries was established from the study:

* To acknowledge thoughts, feelings and experiences;

* To enable the patient to understand experiences from ICU;

* To enable a collective experience of care;

* To develop professional knowledge.

\section{USING PATIENT DIARIES}

A management group with a designated leader has overall responsibility for the 'diary' programme, which consists of four elements:

* A diary kept by nurses, written in the ICU during periods of critical illness, which is handed over to the patients when they are considered able to receive it;

* A follow-up discussion in the form of a meeting between the patient and a nurse from the ICU;

* A visit to ICU;

* A staff meeting where patients' experiences are reflected upon and discussed.

The diary and the follow-up programme consist primarily of writings and meetings about patient care. However, there is also huge potential to improve specialist knowledge of intensive care by learning from patients' experiences. By turning the patient's account into practice, professionals also have a basis for evaluating their own practice and for discussing topics that focus on the development and quality of patient care. In the preliminary study, the staff commented particularly on this aspect.

The leader of the management group is responsible for its co-ordination and the group is responsible for providing advice to the member of staff who writes in the diary. The group is also responsible for reading through and approving the diary in accordance with set guidelines before it is handed over to the patient. Guidelines for diaries and follow-up discussions ensure implementation of the measures within a given framework. The management group evaluates the measures annually and, based on this, may propose changes to the guidelines.

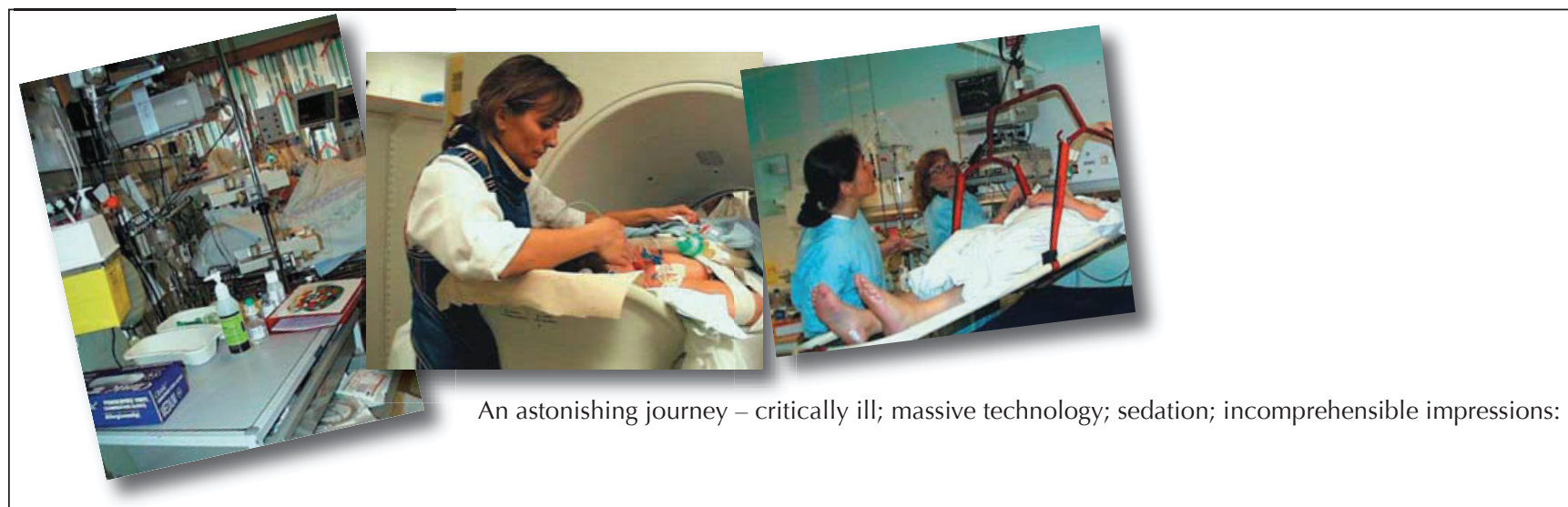

I was in a kind of drum, it was like being inside a tumble dryer...there were several people in pockets inside the dryer... and it went around and around ... and around.'

'I had the feeling that people were dying around me... and that I was declared dead.'

'I felt as if I was nailed up against a wall... but it all began with travelling throughout Europe.'

'I was on a lovely beach... and my father, who died when I was three years old, held me in his arms...' 'It was happening - it was more than $110 \%$ live! I was there! I cannot understand that it didn't actually occur - I was absolutely convinced of its reality!' 


\section{The diary}

The diary is meant to be a narrative in which the patient can find recognition. Through descriptions, photographs and thoughts it can contribute to completing the patient's own experience and make it more comprehensible. The diary contains no medical facts about diagnoses or the patient's condition. However, it should reflect an observation of the patient's appearance and the nurse's description and thoughts about what was observed. A diary written as a conjectural narrative or as a story of wonder will also contain elements of fact, but the basis for the notes is that the patient is a participant in the situations described. Photographs are used to illustrate the text. It is the diversity and the different 'ways' of writing that give the diary fullness.

\section{Writing a diary}

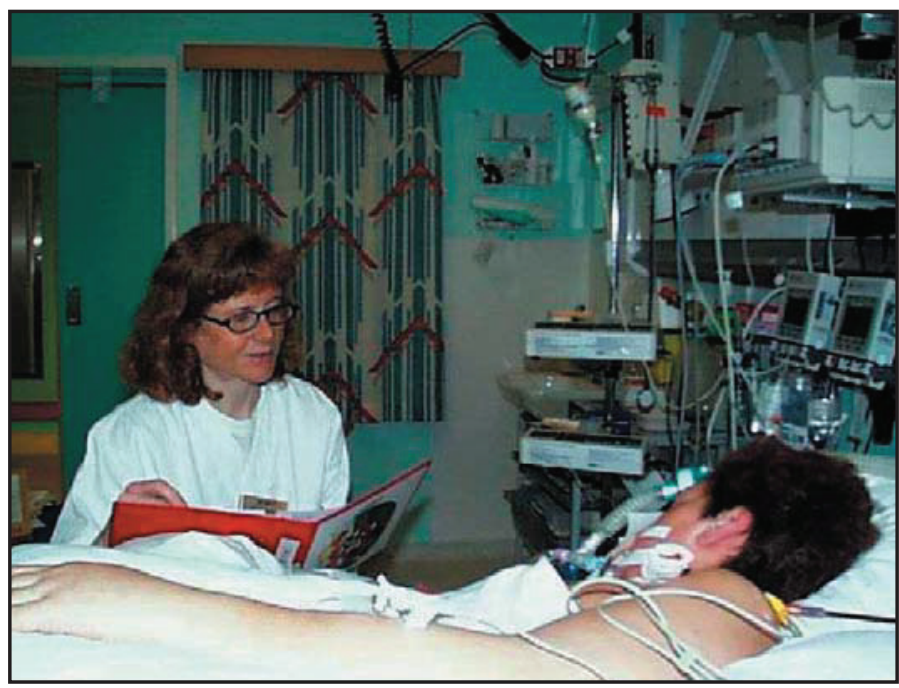

\section{Monday 18th of June}

'You have been lying on your stomach for several hours today. That means that instead of lying on your back or your side we have turned you over, supporting your left side with cushions. We do this because it is good for your lungs and will help your body's uptake of oxygen. I wonder if you usually lie on your stomach when you sleep? You seem so relaxed in this position. I wonder if you will remember lying like this when you are allowed to wake up.'

Christine Lind, intensive care nurse

\section{Sunday, 8th of July}

'The days pass, you struggle on. You are more awake tonight - you open your eyes slightly when I talk to you, turn your head a little. You seem to understand some of what I am saying. You are given eye drops quite often. You squeeze your eyes shut as the drops touch them.

Your bare shoulders above the covers are cold to the touch, your hands too. Are you cold?

I tell you that I think you are. I get you an extra blanket that I tuck around your shoulders and cover your hands.'

Rosa Hansen, intensive care nurse

The text in the diary will provide possibilities rather than stating facts. The language, therefore, must be different to 'medical' language, where precision and objectivity are essential. Normal everyday spoken language is ideal for a diary. Everyday language enables the writer to go back and forth - it gives room for conjecture more than definitive answers.

In principle, diaries should be available to all patients in intensive care. For the scheme to have any significance, the following criteria are adhered to:

* The patient prognosis must indicate that the individual might benefit from the scheme.

* The patient must be expected to stay in intensive care for more than three days.

This means that an evaluation based on these criteria must take place before a diary is started.

The aim is to establish a 'primary team' of nurses for each individual patient. The primary team takes the initiative to evaluate a diary start-up. The pre-start-up, criteria-based evaluation takes place in a multidisciplinary forum to ensure an optimum evaluation of the patient's condition and prognosis. One or two representatives from the management group are responsible for following up the diary and giving advice.

In most cases, because patients are unable to communicate, the diary is started without their consent. When the patient is capable of understanding, the diary is presented as something that they can either accept or reject. If the patient does not want to keep the diary, it is destroyed. The patient's relatives are informed about the diary and its purpose and they are provided with a separate information sheet. If the patient is under age, permission to start a diary is sought from the next of kin.

When the patient is discharged from the ICU, the diary remains in the unit in a sealed envelope. Two nurses from the management group, who have followed up the diary, will read through it before presenting it to the patient. It is handed over when the patient is considered able to take care of it. If the patient is moved to another hospital before being in a position to receive the diary, it is sent in a sealed envelope to the new hospital. The diary is accompanied by a covering letter providing information about it, stating that it should be offered to the patient when their condition allows.

\section{FOLLOW-UP DISCUSSION}

The follow-up discussion is a meeting between the patient and 'their nurse(s)', i.e. the nurses who have had closest contact with the patient and have had most involvement in writing the diary. A close relative sometimes attends. As with the diary, the follow-up conversation focuses on the care of the patient. The discussion facilitates a complementary source of information in which patients can search for pieces of their 'puzzle'; a puzzle that comprises both clear and hazy recollections of dreams and reality. Patients are given an opportunity to talk about their experiences with someone who is qualified to understand, and to ask about things they might not be clear about. The discussion can also facilitate an introduction to the diary or may be used as a method for deepening the themes covered therein. In this way the conversation, as with the diary, helps patients to understand more fully what they have been through.

The goals of the discussion are to:

* focus on the patient's questions and experiences;

* introduce the diary and look closely at the themes that it touches upon;

* understand together;

* acknowledge thoughts, feelings and experiences. 
The aim of the discussion is for it to be more than just a normal daily conversation. Thus, it is necessary for those nurses taking part
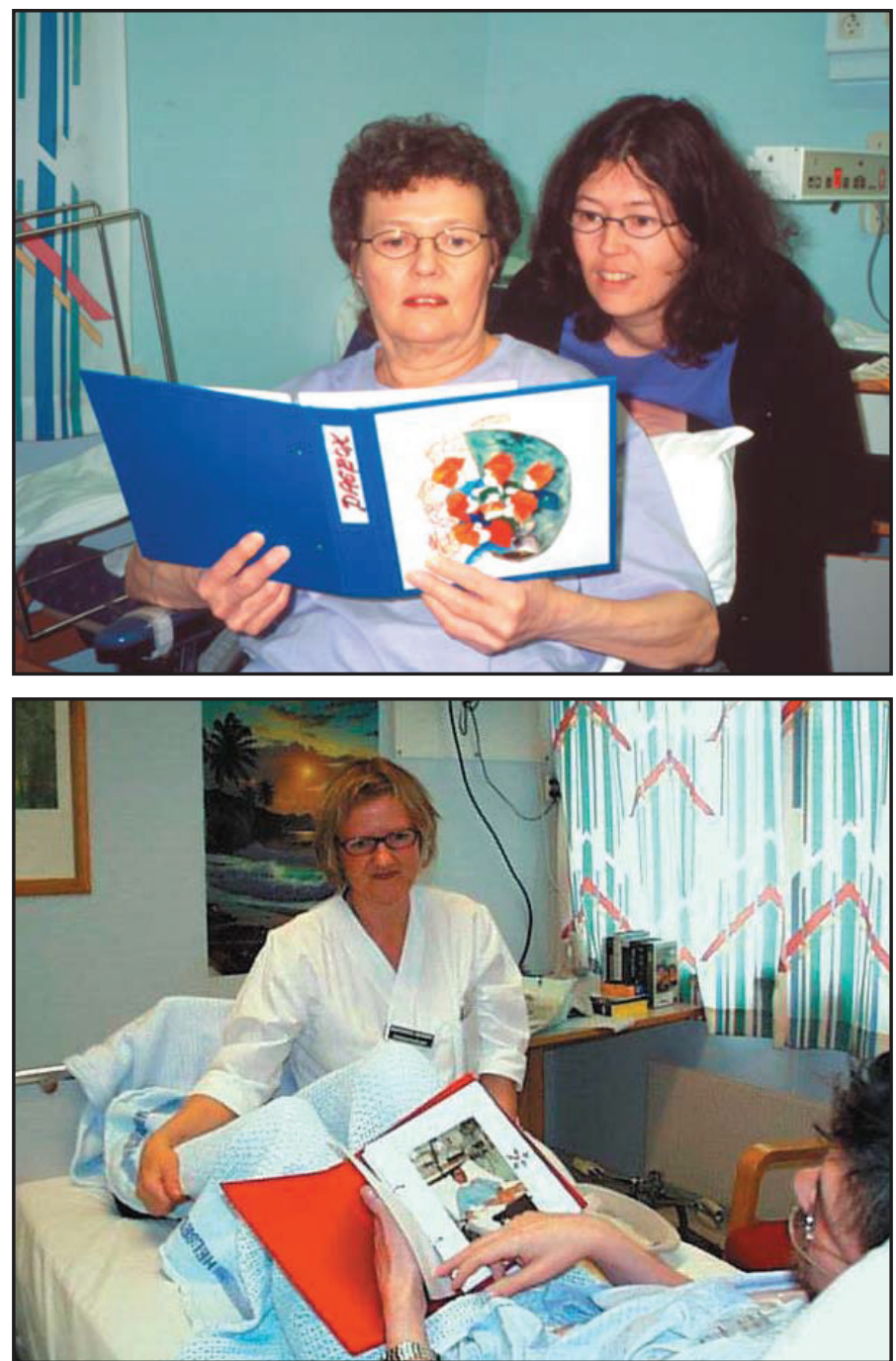

Patients reading their diaries.

to prepare for the meeting. This is particularly important because it may be some time since the patient left ICU. Since then, nurses will have been involved with several new patients and demanding situations, and it is an unrealistic expectation that they remember all the details about a particular patient. The patient's unique experience must be brought to the fore again, and both their case record and nurses' reports are used to provide complementary background information. Our experience also shows that if the nurses who dealt with the patient over time sit down together and 'think out loud' then the patient's care is soon remembered. This is good preparation for the meeting. However, it is important to remind ourselves that the purpose of the conversation is to focus on the patient's experiences and recollections.

The discussion should be kept private and protected from interruptions and other disturbances. Key words in this context are 'quiet' and 'focused'. Although we have a conversation guide that outlines areas on which the conversation might touch, our experience shows that patients often have so much to relate that the conversation runs itself, and little guidance or prompting is needed. One question that has proved to be a catalyst for lengthy accounts from patients is: 'Did you dream a lot or have strange experiences during this period?' Another particularly challenging area is the patients' recollection of communicating with others: did they understand what was said to them and how did they experience their own ability to communicate? It must be remembered, however, that general questions should never draw the focus away from the individual patient with his/her unique story and questions.

The patient is asked beforehand for permission to keep notes from the conversation. The focus must, however, always be on the patient and not on the notes, and sometimes the situation tells us intuitively to put pen and paper aside.

\section{Visiting the ICU}

If, during the conversation, the patient expresses a desire to visit the ICU, or if the primary nurse or nurses regard it as important for a patient's understanding of their experiences to do so, a visit to the ICU is arranged.

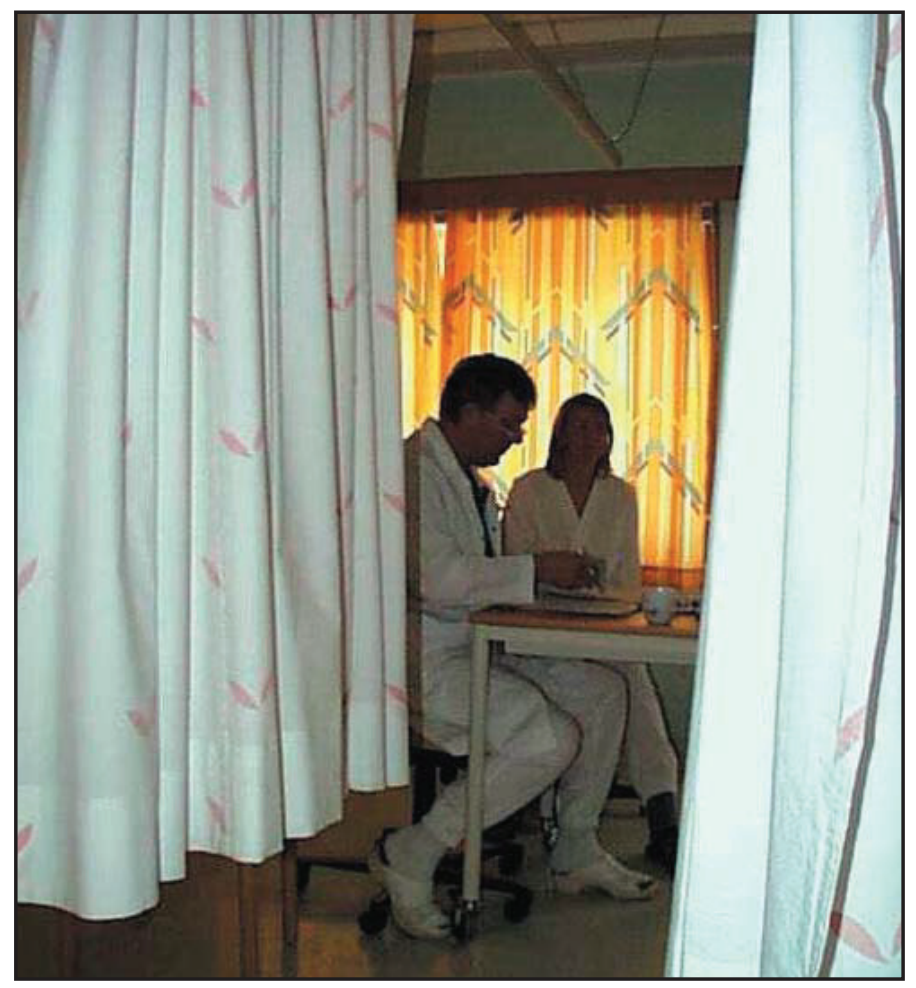

Visiting the ICU: an opportunity to look, listen, smell, feel, recognise..

\section{FOLLOW-UP STAFF MEETING}

Notes from the above discussion are written in narrative form, including quotes from the patient. A permanent multidisciplinary forum is established for dealing with patients' experiences and for discussing problems related to them. The forum is organised and led by members of the management group in co-operation with nurses who have implemented follow-up discussions with patients. The anonymised patient narratives are kept in a separate folder, which is available to staff. The purpose of the meeting is to hear how the patient is progressing, to use the patient's story as a starting point for new learning, and to develop understanding. 


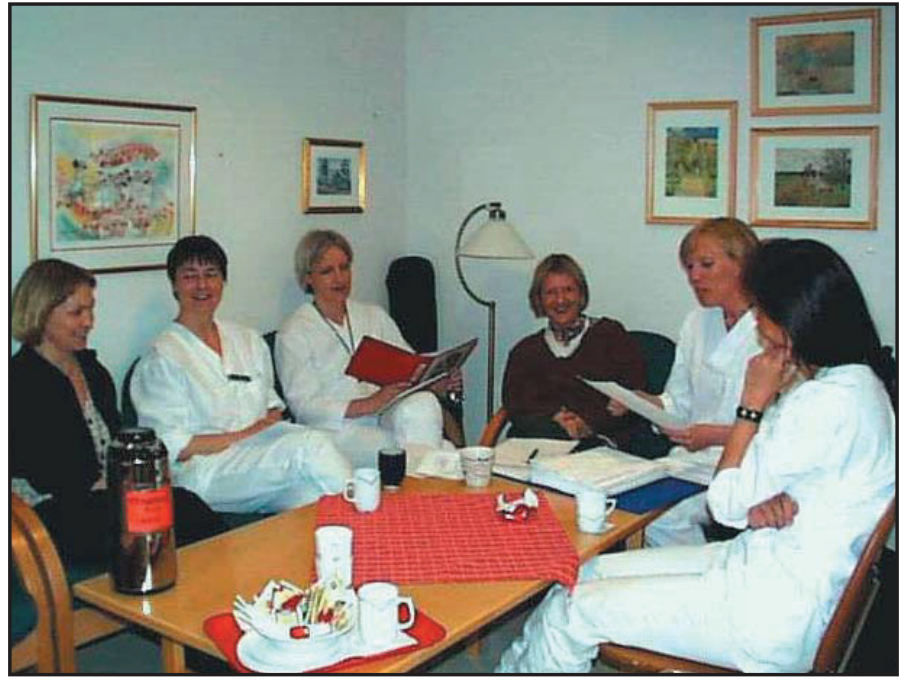

The follow-up staff meeting.

\section{A CASE HISTORY}

The following case history is presented to illustrate our programme in practice. 'Anna' (a pseudonym) is a 58-year-old woman who underwent cardiac surgery and suffered complications due to cardiac failure and respiratory problems. As a result of this she had a prolonged stay in ICU. During the first days, Anna's condition was critical and unstable. On the third day we started writing her diary. A primary care team cared for Anna, wrote in her diary and pasted in photographs. On the seventh day Anna's sedation was reduced and she gradually woke up. She was physically restless but seemed to give appropriate responses when spoken to. Her husband was with her most of the day. Unfortunately for Anna she developed further complications, which required that she be resedated. On the twelfth day Anna was given a tracheostomy and weaning from the ventilator began.

Anna made good progress, managing to use the voice valve to speak. She was quiet and co-operative. However, she used words that the nurses could not understand, which appeared to have no relevance to her situation. The words were recorded ' with wonder' in her diary and sections of dialogue with her were also noted. By day 21 Anna was mobile and she was extubated. She was transferred to the ward the following day.

The diary was approved by the management group and was offered to Anna by the diary co-ordinator on day 25. Anna was introduced to it through the photographs. The follow-up discussion was arranged for the following week. It took place in the patient's room with a nurse from ICU, Anna's husband and a nurse from the management group.

'Everything is chaos from my stay in ICU,' stated Anna. She remembered quite clearly the last days there, but that for a long time she thought that she was in a completely different place, where strange things happened. She thought she had been in dangerous situations:

I was in a military hospital in London where they were going to do experiments on me, but my husband came and rescued me!'

As an afterthought she says, 'But a lot of this has to do with real life, the life that I have lived.'

Through discussion, we were able to help Anna make connections to real impressions and events.

Before Anna left for home, she visited the ICU to look, listen, smell and perhaps recognise something. She did not remember the ventilator, but recognised its breathing sounds and the characteristic noise of the suction as sounds from 'the hospital in London'. The staff follow-up meeting was held three days later and Anna's account was discussed.

Three months later Anna telephoned the ICU to tell us that she was fine, but that her rehabilitation process was taking time. She thanked us again for the diary saying, 'Just imagine that you took the time to do this...you have no idea what it means to me...that somebody cared about my thoughts - not just my organs!'

\section{PATIENTS' AND STAFF'S COMMENTS}

Anna's comment, above, is by no means unusual. Many patients have expressed similar thoughts. Some examples are given below, which illustrate graphically how successful the diary is - from the patient's perspective:

'It means so much to me that you thought about how I really felt... that you cared about me..."

'I haven't been able to read so much in the diary yet...I cry so easily.'

I have been on a journey through several different countries...in my world I haven't been in intensive care in Tromsø at all. Now I start to realise...there are some connections... and I can get a grip of my madness...'

'The diary and our chat give me insight...that I now realise to some extent how sick I really was and why my body is so altered, so....wretched! But last and not least that I have some clue as to what really happened.'

Nurses also find the diary a very valuable tool for practice. Given below is a selection of comments from colleagues:

'Writing the diaries and the patients' accounts make us more aware that each patient is unique and that our approach to the patients can be experienced very differently from patient to patient.'

'To be given the opportunity to meet the patient after their discharge is important in order to keep us motivated in our work in intensive care.'

'The follow-up routine gives opportunities for valuable discussions on patient care.'

'By writing the diaries I often see the patient in a new light and that makes a difference to my work. Writing gives me the opportunity to sum up my day and highlight the challenges.'

\section{CONCLUDING REMARKS}

Knowing so much today about the patients' struggle to make sense of their ICU experiences, we almost have a moral obligation to do something about it. We cannot simply overlook the fact that there is more to recovering from intensive care than physical recovery. However, more research is needed to inform the development of follow-up programmes for the future. On the basis of our initial study and through our clinical experiences of several years of working with follow-up programmes, we know that sources for understanding, like diaries and follow-up discussions, have a significant impact on patients' ability to live with their ICU experiences. To be able to argue for and develop schemes, we need to gain a deeper insight into what really matters to our patients.

\section{ACKNOWLEDGEMENT}

The poster presentation (Storli 2002), from which this paper was developed, was supported by The Laerdal Foundation for Acute Medicine, Psychiatric Research Centre for the Counties Finnmark and Troms, The University of Tromsø, and by The University 
Hospital of North Norway, Tromsø.

\section{REFERENCES}

Bergbom, I, Svensson, C, Berggren, E \& Kamsula, M. (1999) Patients' and relatives' opinions and feelings about diaries kept by nurses in an intensive care unit: pilot study. Intensive and Critical Care Nursing 15 (4), 185-191.

Compton, P. (1991) Critical illness and intensive care: what it means to the client. Critical Care Nursing 11 (1), 50-56.

Daffurn, K, Bishop, GF, Hillman, KM \& Bauman, A. (1994) Problems following discharge after intensive care. Intensive and Critical Care Nursing 10 (4), 244-251.

Gjengedal, E. (1994) Understanding a World of Critical Illness. A Phenomenological Study of the Experiences of Respirator Patients and their Caregivers. University of Bergen, Norway.

Granberg, A, Bergbom Engberg, I \& Lundberg, D. (1998) Patients' experience of being critically ill or severely injured and cared for in an intensive care unit in relation to the ICU syndrome. Part I. Intensive and Critical Care Nursing 14 (6), 294-307.

Granberg, A, Bergbom Engberg, I \& Lundberg, D. (1999) Acute confusion and unreal experiences in intensive care patients in relation to the ICU syndrome. Part II. Intensive and Critical Care Nursing 15 (1), 19-33.
Jones, C, Humphris, G \& Griffiths, R. (1998) Psychological morbidity following critical illness - the rationale for care after intensive care. Clinical Intensive Care 9 (5), 199-205.

Jones, C, Griffiths, R, Humphris, G \& Skirrow, P. (2001) Memory, delusions, and the development of acute post-traumatic stress disorder-related symptoms after intensive care. Critical Care Medicine 29 (3), 573-580.

Lind, R \& Storli, S. (1999) Rapport prosjekt Dagbok og Oppfølgingssamtale [Following up patients: an evaluation]. ICU, University Hospital of North Norway, Tromsø, Norway. Løgstrup, KE. (1956) The Ethical Demand. Philadelphia, Fortress Press. Merleau-Ponty, M. (1962) Phenomenology of Perception. Routledge, London.

Storli, S. (2000) Virksomhetsbeskrivelse Dagbok og Oppfølgingssamtale [Following up patients in intensive care: a description of the method]. ICU, University Hospital of North Norway, Tromsø, Norway.

Storli, S. (2002) The 'Astonishing Journey' - a phenomenological perspective on patients' experiences of being cared for in the ICU. Paper presented at The 1st Conference of the European Federation of Critical Care Nursing Associations, Paris 2002. 